\title{
FIELD EXCITATION AND DISCHARGE SWITCHING FOR AIR-CORE COMPULSATORS
}

\author{
R.F. Thelen \\ Center for Electromechanics \\ The University of Texas at Austin \\ PRC, MC R7000 \\ Austin, TX 78712 \\ (512) $471-4496$
}

\begin{abstract}
The Center for Electromechanics at The University of Texas (CEM-UT) has designed and built three generations of air-core compulsators for railgun application. These systems rely on compact power electronics to provide rapid self-excitation of the field windings and control of the main current discharge. All three systems built so far have been single-phase armature machines. The parameters for these systems range from 20 to $42 \mathrm{kA}$ field excitation at 125 to $400 \mathrm{~Hz}$ rectification and 2.5 to $12 \mathrm{kV}$. The main discharge peak current ranges from 0.3 to $3 \mathrm{MA}$. The design and performance of past switching systems is reviewed and the prospects for further mass and volume reductions is presented.
\end{abstract}

\section{Introduction}

Since 1986, CEM-UT has been developing air-core compulsators to drive various railgun applications. The aircore compulsator is distinguished by the absence of ferromagnetic materials in the magnetic circuit of the machine. These nonferrous machines achieve a higher energy density by using composite rotor structures which can be spun to greater stress levels than previous iron-core rotor designs. The lack of a ferromagnetic circuit, however, means that much greater field current is required for comparable voltage generation. Overall system power density is maintained by causing the machine to self-excite the field winding. This is achieved by rectifying armature alternating output and applying the conditioned current to the field winding. Power electronic systems have been built to accommodate the requirements of field excitation and to control the pulse discharge for the railgun operation. Previous papers have disclosed aspects of these switches ${ }^{1,2,3}$. Figure 1 shows, schematically, the variety of circuits employed.

The Small Caliber Electromagnetic (EM)

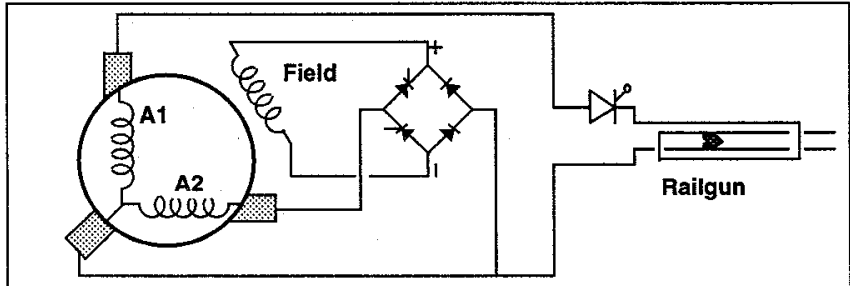

Figure 1a. Small Caliber EM launcher circuit schematic

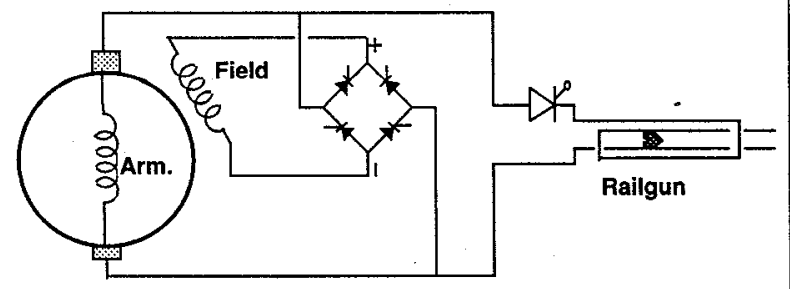

Figure 1b. Cannon Caliber EM gun circuit schematic

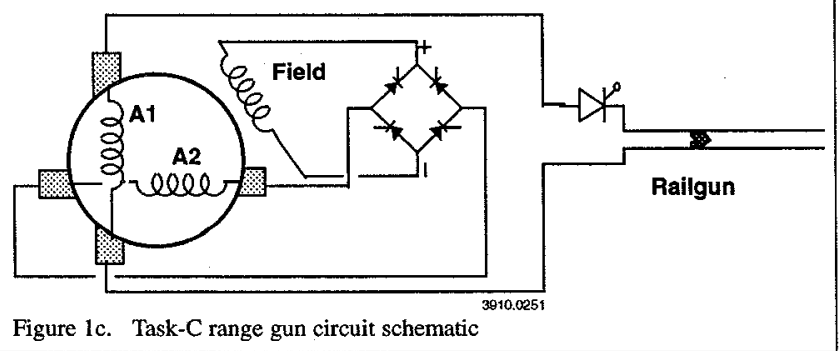

Launch System (SmCal) objective was a compact, lightweight test bed capable of accelerating a salvo of three, $32 \mathrm{~g}$ masses $(0.60$ caliber) to $2 \mathrm{~km} / \mathrm{s}$ at a rate of $10 \mathrm{~Hz}$. This system was tested at CEM-UT between October 1991 and May 1994 ${ }^{4}$. The Cannon Caliber EM Gun Program (CCEML) is currently being tested at CEM-UT ${ }^{5}$. CCEML includes a lightweight compulsator to drive 15 projectiles of $185 \mathrm{~g}$ to over $1.8 \mathrm{~km} / \mathrm{s}$ in three 5 -shot salvos, firing at $5 \mathrm{~Hz}$. The 9MJ Range Gun System (Task-C) was designed as a field portable EM launch system to accelerate a salvo of nine $90-\mathrm{mm}$ projectiles over three minutes to a muzzle energy of $9 \mathrm{MJ}$ with velocities between 2.5 and $4 \mathrm{~km} / \mathrm{s}^{6}$. This project was discontinued in early 1995 due to program funding cuts.

In each system, two switching requirements are addressed. The railgun switch carries much greater current and $\mathrm{I}^{2} \mathrm{t}$ rating for much shorter time frame than the field excitation bridge switching. The bridge operates for up to several hundred machine cycles, while the railgun launch time varies from 1.5 to $6 \mathrm{~ms}$ (table I). The SmCal system employed a halfcontrol bridge and was the first to demonstrate aircore self excitation. The SmCal field winding inductive energy was allowed to dissipate in a freewheeling circuit after each gun shot. The other two systems 
Table 1. Air core compulsator electrical design parameters

\begin{tabular}{|l|c|c|c|c|}
\hline & SmCal & CCEML & Task-C & Units \\
\hline Open-circuit voltage peak, A1 & 2.4 & 3.8 & 5.8 & $\mathrm{kV}$ \\
\hline Open-circuit voltage peak, A2 & 4.4 & - & 12 & $\mathrm{kV}$ \\
\hline Electrical frequency & 400 & 400 & 130 & $\mathrm{~Hz}$ \\
\hline Field charging V[max] - avg. & 2.8 & 2.4 & 6.8 & $\mathrm{kV}$ \\
\hline Field current max. & 4.8 & 25 & 41.5 & $\mathrm{kA}$ \\
\hline Time to peak field & 570 & 67 & 850 & $\mathrm{~ms}$ \\
\hline Railgun launch current (peak) & 400 & 825 & 3200 & $\mathrm{kA}$ \\
\hline Launch pulse width & 1.5 & 1.5 & 5.6 & $\mathrm{~ms}$ \\
\hline Number of shots in mission & 3 & 15 & 9 & \\
\hline Ratio gun I[pk] to field i[pk] & 80 & 33 & 76 & \\
\hline
\end{tabular}

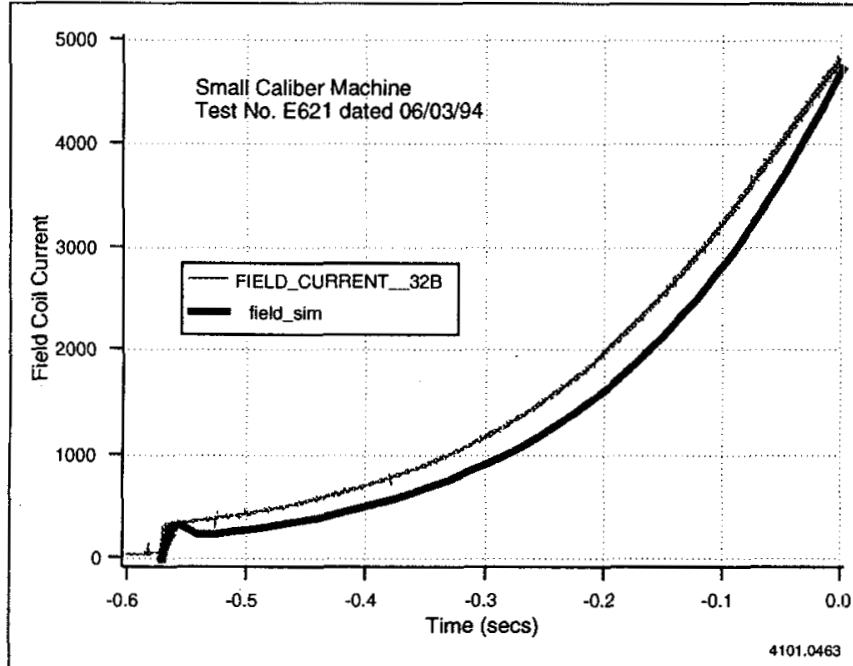

Figure 2. SmCal field excitation to $4,800 \mathrm{~A}$ measured and predicted

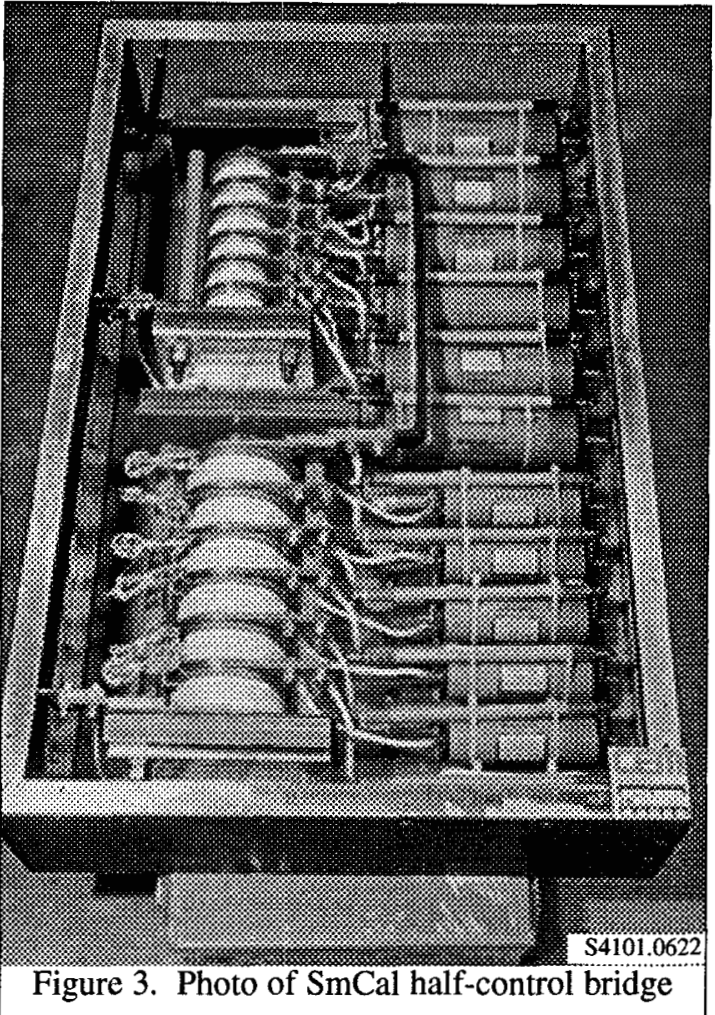

improve system efficiency by using a full-control bridge and shift phase control after the gun shot to recover field winding stored energy to the rotor flywheel storage.

\section{Field Excitation}

Field excitation for the SmCal system performed well, closely matching predicted current rise times (fig. 2). Figure 3 is a picture of the half-control bridge packaged for this system. All of the power electronics described in this paper employ inertial cooling since the duty is short. Copper at the device pole face is calculated to provide sufficient thermal mass to control the temperature rise. A fielded electric gun system would also use inertial cooling of the semiconductor junctions but might augment convection cooling of the heat sinks for more on-going cycle times.

The CCEML bridge has not been tested as of this writing. The plan for this bridge assembly is shown in figure 4. The snubber circuit for this bridge was built around each group of 3-parallel thyristors in an attempt to further reduce the bridge volume and mass. This bridge is full control, allowing the energy stored inductively in the field winding $\left[\mathrm{U}(\mathrm{fld})=\mathrm{LI}^{2} / 2\right]$ to be recovered after the railgun discharge. The energy is recovered to the flywheel storage of the compulsator rotor [U(rotor) $=\mathrm{J} \omega^{2} / 2$ ]. Figure 5 shows a plot of predicted field charging and recovery timing. The air-core compulsator begins self-excitation by the capacitive discharge of seed current into the field winding. Table II is a comparison of various bridge parameters between the three projects. The maximum field energy recovered correlates with field charging efficiency, and translates directly into heat not dissipated and prime-mover power not required.

The Task-C system also employs a full control, single phase bridge (fig. 6). This much larger system conditions a peak power of $600 \mathrm{MW}$ when field excitation reaches rated levels (fig. 7). Table III shows a reduction of the bridge parameters to a per-device basis to facilitate packaging comparisons. The Task-C volume-per-device is comparable to the other projects $(4,867 \mathrm{cc})$ when the enclosure is removed. This bridge uses inductors in series with each parallel path to insure current sharing, because of the larger number of parallel paths involved. 


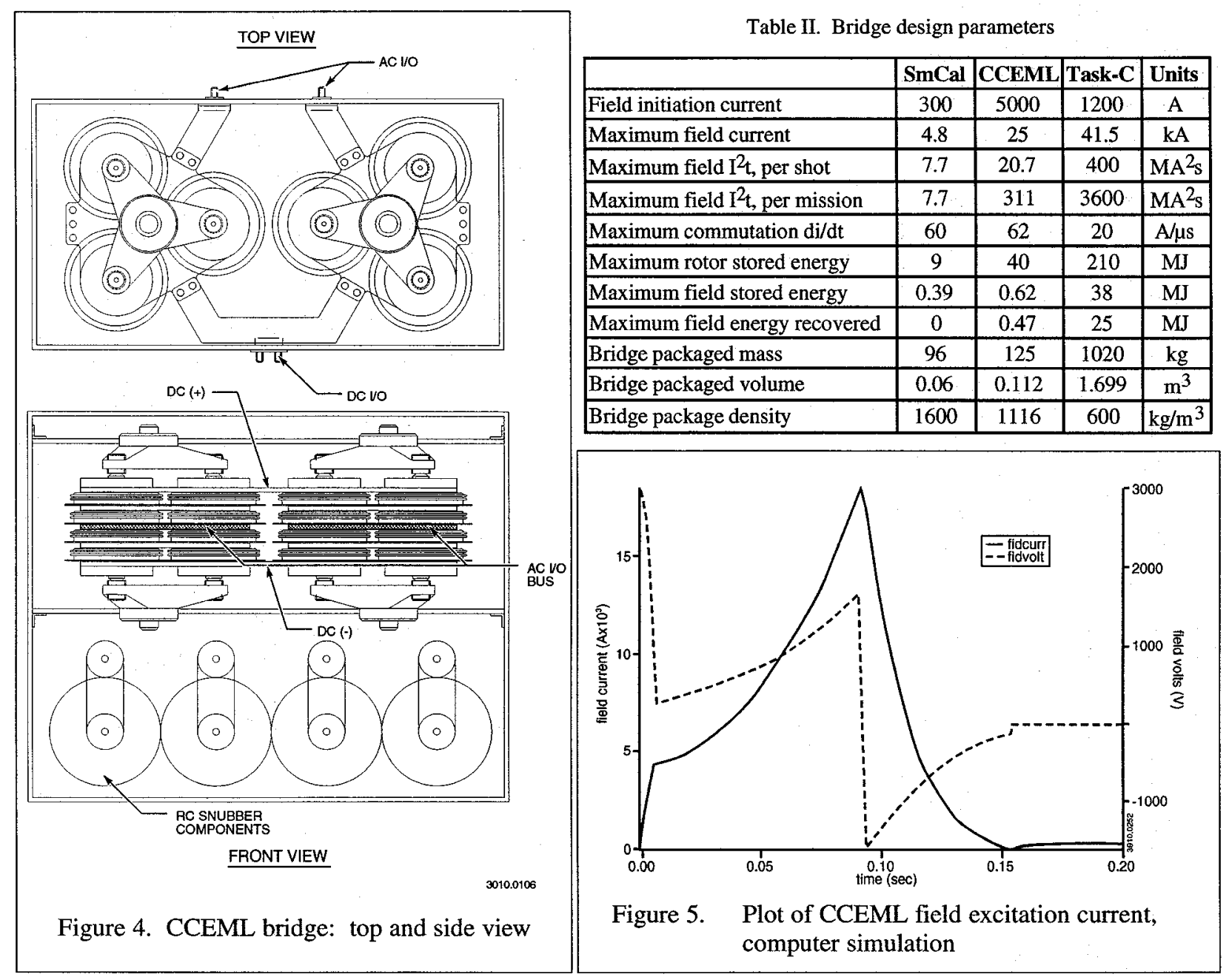

As compulsator system designs strive for higher energy density, the trend for field excitation will be toward higher frequency and higher gain. Higher frequency is the result of more compulsator poles and/or rotation speed, both of which reduce machine size. The gain of the field exciter circuit is a function of the volts generated per field amp and the resistance and inductance of the field circuit. Higher gain systems drive field current from initiation to full level in shorter time (fewer cycles). This results in lower $I^{2} t$ action for the field winding and the bridge, allowing smaller components with respect to thermal capacity. Higher field current magnitude also results, however, because high gain field windings have fewer turns to reduce inductance. So, while the switch $\mathrm{I}^{2} \mathrm{t}$ is alleviated, the switch absolute current and di/dt handling is aggravated. Table IV shows the above parameters for the three system. CCEML is the latest circuit design and shows the application of this trend to faster field charging. High field charging efficiency is required to avoid dissipated heat losses and to realize appreciable energy recovery from inverting. The low numbers for $\mathrm{SmCal}$ indicate a poor opportunity to benefit from full bridge control.

\section{Railgun Switching}

The SmCal and CCEML load switches are both single series switches which attempt a snubberless operation. The SmCal switch had partial success in this matter. When the delivery of higher voltage thyristors $(3,400 \mathrm{~V})$ was delayed, a set of off-the-shelf devices $(1,800 \mathrm{~V})$ from Westcode were purchase to allow early, lower voltage testing of the machine.These devices had faster recovery and better matched performance than the lot from IR-Canada which were produce in a limited production for the higher voltage. Eventually higher voltage operation required that a snubber be added across the entire switch. Figure 8 shows the 16-junction switch of SmCal and figure 9 shows CCEML's 40-junction switch.

The Task-C system involves higher voltage and much more current. The railgun switch is divided into two banks of 12 gun switch module (GSM) arrays. Each GSM relies on thyristor matching to assure current and voltage 


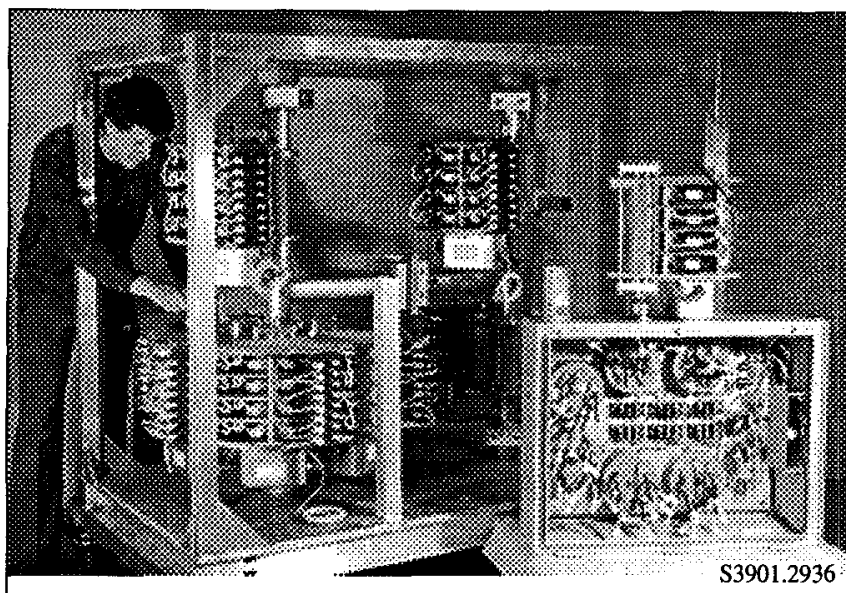

Figure 6 . Task-C bridge partially assembled with 1 of 4 required gating circuits (foreground)

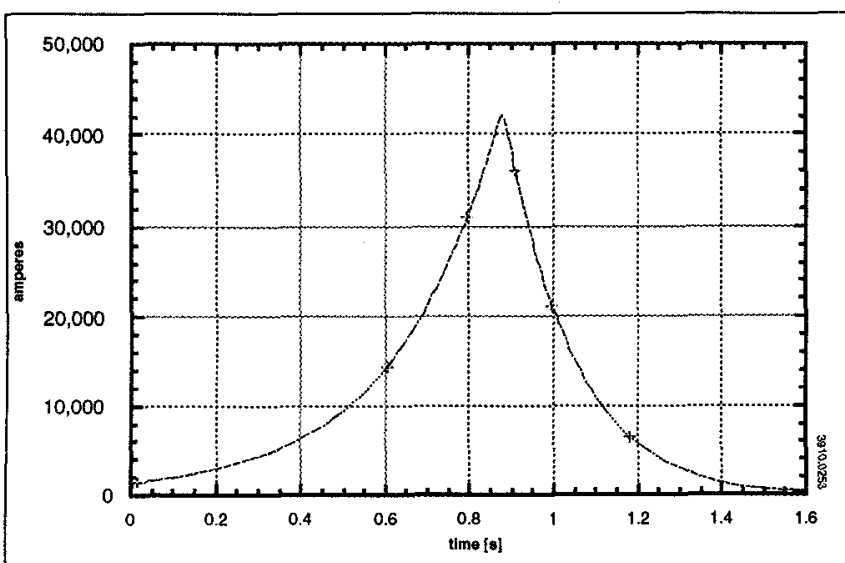

Figure 7. Plot of Task-C field excitation current, computer simulation

Table III. Bridge parameters per SCR device

\begin{tabular}{|l|c|c|c|}
\hline & SmCal & CCEML & Task-C \\
\hline Number of junctions in bridge & 12 & 24 & 192 \\
\hline Number of junctions in series & 3 & 2 & 8 \\
\hline Number of junctions in parallel & 1 & 3 & 6 \\
\hline Bridge mass per device $(\mathrm{kg})$ & 8.00 & 5.21 & 5.31 \\
\hline Bridge volume per device $(\mathrm{cc})$ & 5000 & 4667 & 8849 \\
\hline Mission action per p-path $\left(\mathrm{MA}^{2}\right.$ s) & 3.850 & 17.278 & 50.000 \\
\hline Shot action per p-path(MA ${ }^{2}$ s) & 3.850 & 1.150 & 5.556 \\
\hline
\end{tabular}

Table IV. Field charge circuit gain and efficiency

\begin{tabular}{|l|c|c|c|c|}
\hline & SmCal & CCEML & Task-C & Units \\
\hline Field charging V(avg) & 2800 & 2400 & 6800 & $\mathrm{~V}$ \\
\hline Field current, maximum & 4800 & 25000 & 41500 & $\mathrm{~A}$ \\
\hline Field circuit resistance & 0.250 & 0.023 & 0.048 & $\Omega$ \\
\hline Field circuit inductance & 0.034 & 0.002 & 0.047 & $\mathrm{H}$ \\
\hline Field circuit gain [(k-R)/L] ${ }^{*}$ & 9.80 & 37.01 & 2.47 & $1 / \mathrm{s}$ \\
\hline Field charging efficiency [1-R/k] & 57.14 & 76.49 & 70.71 & $\%$ \\
\hline${ }^{*} \mathrm{k}=\mathrm{V}[\mathrm{avg}] / \mathrm{I}$ & 0.583 & 0.096 & 0.164 & $\Omega$ \\
\hline
\end{tabular}

sharing among its 12 junctions. Cable impedance to each GSM helps further current sharing among modules. Table $V$ summarizes the switch requirements of the three projects. To reduce the mass and volume of the 288 junction array, a minimized device package (fig. 10) was developed with the manufacturer (the former GE-SPCO, Malvern, Pa.). This same product was used in both the bridge and the gun switch. The reduced package was more effective in the gun switch where the required inertial cooling was much less than the bulk of copper usually provided by the conventional "hockey puck" package. The Task-C gun switch uses $1.6 \mathrm{~mm}$ copper to provide electrical connection and cooling conduction to the SCR junctions, whereas the bridge has $19 \mathrm{~mm}$ copper thickness.

All three system gun switches were required to carry a single current surge (half cycle) followed by reverse applied voltage during switch recovery. The repetition rate of the smaller two systems involved some residual heat in the junction for subsequent salvo shots, but Task-C switches are fully cooled from a $100^{\circ} \mathrm{C}$ junction excursion to a few degree celcius rise in the copper after about $2 \mathrm{~s}$. Table VI shows the per-device normalization for the three projects. The SmCal gun switch was built to be robust but was not optimized with regard to mass and volume like the other two projects were. The benefit of thin SCR packaging explains the lower mass per device for Task-C, however the snubber circuits added to the volume expenditure.

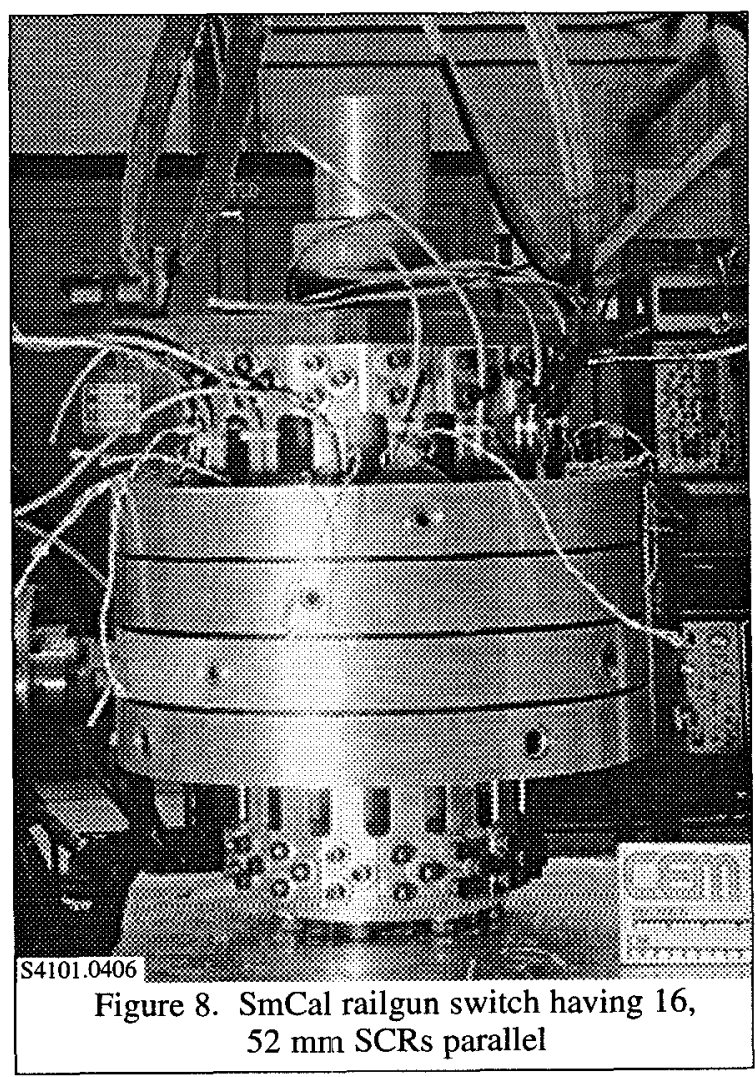




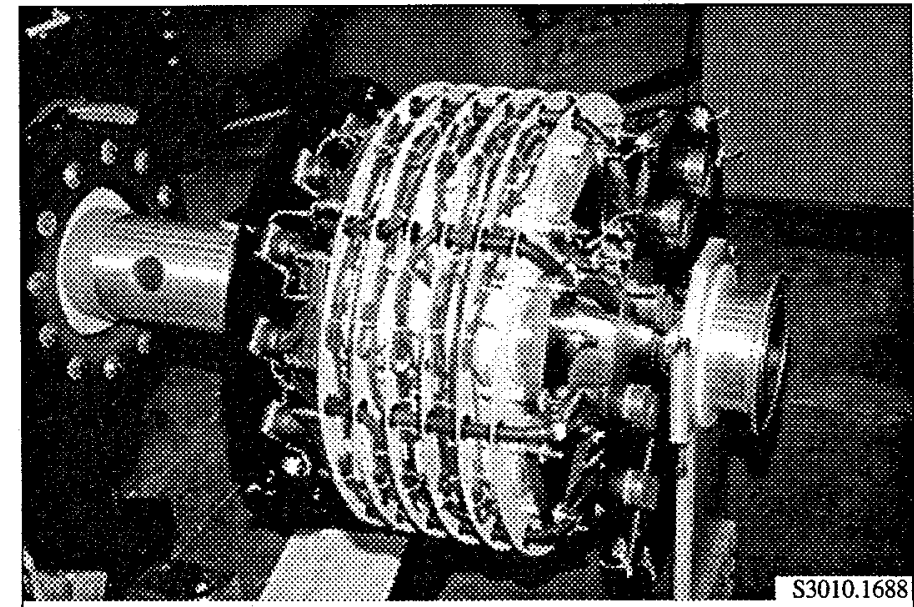

Figure 9. CCEML railgun switch having $40,77 \mathrm{~mm}$ SCRs parallel

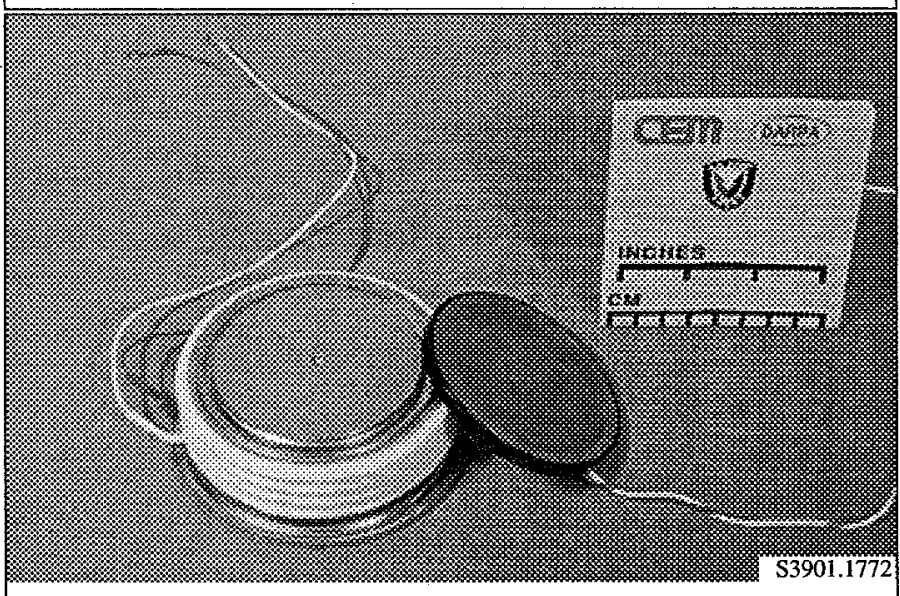

Figure 10. Thin-pak SCR along side customary presspak design

Table V. Gun switch design parameters

\begin{tabular}{|l|c|c|c|c|}
\hline & SmCal & CCEML & Task-C & Units \\
\hline Maximum gun current & 400 & 834 & 3200 & $\mathrm{kA}$ \\
\hline Maximum gun I ${ }^{2}$, per shot & 125 & 624 & 30,000 & $\mathrm{MA}^{2} \mathrm{~s}$ \\
\hline Maximum gun I ${ }^{2}$, per mission & 375 & 9440 & 270,000 & $\mathrm{MA}^{2} \mathrm{~s}$ \\
\hline Maximum di/dt & 800 & 2000 & 3000 & $\mathrm{~A} / \mu \mathrm{s}$ \\
\hline Gun switch packaged mass & 105 & 102 & 689 & $\mathrm{~kg}$ \\
\hline Gun switch packaged volume & 0.085 & 0.126 & 1.384 & $\mathrm{~m}^{3}$ \\
\hline Gun switch package density & 1233 & 810 & 498 & $\mathrm{~kg} / \mathrm{m}^{3}$ \\
\hline
\end{tabular}

Table VI. Gun switch parameters per SCR

\begin{tabular}{|l|c|c|c|c|}
\hline & SmCal & CCEML & Task-C & Units \\
\hline Number of junctions in gun switch & 16 & 40 & 288 & \\
\hline \# series in gun switch & 1 & 1 & 2 & \\
\hline \# parallel in gun switch & 16 & 40 & 144 & \\
\hline Gun switch mass per device & 6.56 & 2.55 & 2.39 & $\mathrm{~kg}$ \\
\hline Gun switch volume per device & 5322 & 3150 & 4806 & $\mathrm{cc}$ \\
\hline Mission action per p-path & 1.465 & 5.900 & 13.021 & $\mathrm{MA}^{2} \mathrm{~s}$ \\
\hline Shot action per p-path & 0.488 & 0.390 & 1.447 & $\mathrm{MA}^{2} \mathrm{~s}$ \\
\hline
\end{tabular}

Future applications of compulsator-railgun systems will tend toward higher frequencies, including multiple pulses to the gun during launch. These actions make most system components smaller and lighter weight. The launch window is set by external considerations like payload characteristics (maximum acceleration, jerk, mass, etc.), so the total launch times will not likely change much. The machine voltage will run about like the Task-C maximum of $12 \mathrm{kV}$. Voltages above $15 \mathrm{kV}$ lose machine density advantage since insulator dimensions begin to overcome gains made in conductor dimensions. The general railgun relationships are:

$$
\begin{aligned}
& \mathrm{V}_{\text {velocity }}=\frac{\mathrm{L}^{\prime}}{2 \mathrm{~m}} \cdot \mathrm{I}^{2} \mathrm{t} \\
& \mathrm{U}_{\text {muzzle }}=\frac{1}{2} \mathrm{mv}^{2}=\left(\frac{1}{2 \mathrm{~m}}\right) \cdot\left(\frac{\mathrm{L}^{\prime}}{2}\right)^{2} \cdot\left(\mathrm{I}^{2} \mathrm{t}\right)^{2}
\end{aligned}
$$

From these, a $20 \mathrm{MJ}(3 \mathrm{~km} / \mathrm{s}, 4.4 \mathrm{~kg})$ shot from a $0.5 \mu \mathrm{H} / \mathrm{m}$ railgun requires an action $\left(\mathrm{I}^{2} \mathrm{t}\right)=5.3 \mathrm{x}$ $10^{10} \mathrm{~A}^{2} \mathrm{~s}$, and an average $5 \mathrm{~ms}$ current of $3.3 \mathrm{MA}$. The current waveform is bounded between square wave and sinusoid, so the peak current is between 3.3 MA and 4.6 MA. If the launch is driven by 1 to (say) 10 pulses, machine frequency lies between 150 and $1,000 \mathrm{~Hz}$. This leads to a maximum di/dt requirement of $\omega \mathrm{I}(\max )$ between 4 and $29 \mathrm{kA} / \mu \mathrm{s}$ over the frequency range.

In order to see some goals for future switch development, it is useful to examine the implications of the past three air-core compulsator systems. The $20 \mathrm{MJ}$ railgun system would call for a power supply mass of $4,500 \mathrm{~kg}$ and volume of about $2.5 \mathrm{~m}^{3}$. At higher frequency, compulsator size reduction is offset by added switch volume and mass to accommodate multiple phases and higher $\mathrm{di} / \mathrm{dt}$ and voltage. Table VII shows how mass and volume for the compulsators and switching subsystems distributed in the three prior projects. The projected system extrapolates from the preceding patterns. From this a gun switch of $247 \mathrm{~kg}(46 \%)$ and $0.278 \mathrm{~m}^{3}(54 \%)$ and excitation conditioning of $293 \mathrm{~kg}(56 \%)$ and $0.222 \mathrm{~m}^{3}(44 \%)$ is indicated. Furthermore, if we allow $5,000 \mathrm{cc}$ per device package, a total of 55 devices are implied for the gun switch.

Some device characteristics can be identified which would contribute to the ultimate goal for switch size. An idealized future switch element would avoid voltage grading issues by withstanding system voltage plus transients: i.e., symmetrical voltage rating exceeding $25 \mathrm{kV}$. The device 
Table VII. Compulsator and switching mass and volume portion

\begin{tabular}{|c|c|c|c|c|}
\hline & SmCal & CCEML & Task-C & $\begin{array}{c}\text { Projected } \\
\text { System }\end{array}$ \\
\hline System mass $(\mathrm{kg})$ & 1252 & 2452 & 27699 & 4500 \\
\hline Percent for compulsator & $69 \%$ & $82 \%$ & $89 \%$ & $80 \%$ \\
\hline Percent for switching & $16 \%$ & $9 \%$ & $6 \%$ & $12 \%$ \\
\hline gun switch & $52 \%$ & $45 \%$ & $40 \%$ & $46 \%$ \\
\hline bridge & $48 \%$ & $55 \%$ & $60 \%$ & $54 \%$ \\
\hline System volume $\left(\mathrm{m}^{3}\right)$ & 0.568 & 1.338 & 12.283 & 2.5 \\
\hline Percent for compulsator & $39 \%$ & $64 \%$ & $65 \%$ & $66 \%$ \\
\hline Percent for switching & $26 \%$ & $18 \%$ & $25 \%$ & $20 \%$ \\
\hline gun switch & $59 \%$ & $53 \%$ & $55 \%$ & $56 \%$ \\
\hline bridge & $41 \%$ & $47 \%$ & $45 \%$ & $44 \%$ \\
\hline
\end{tabular}

Table VIII. Hypothetical switch element characteristics

\begin{tabular}{|l|c|c|c|c|}
\hline & $\begin{array}{c}\text { Future } \\
\text { Switch } \\
\text { Element }\end{array}$ & $\begin{array}{c}\text { Silicon } \\
\text { SCR } \\
\text { (typical) }\end{array}$ & $\begin{array}{c}\text { Vacuum } \\
\text { Gap }\end{array}$ & $\begin{array}{c}\text { SiC } \\
\text { SCR }\end{array}$ \\
\hline Device mass $(\mathrm{kg})$ & 4.5 & $\sqrt{ }$ & 9 & $\sqrt{ }$ \\
\hline Device volume $(\mathrm{cc})$ & 5000 & $\sqrt{ }$ & $\sqrt{ }$ & $\sqrt{ }$ \\
\hline $\begin{array}{l}\text { Operating device maximum } \\
\text { current }(\mathrm{kA})\end{array}$ & 84 & $\sqrt{ }$ & $\sqrt{ }$ & $\sqrt{ }$ \\
\hline Operating device di/dt $(\mathrm{A} / \mu \mathrm{s})$ & 600 & 300 & 200 & $\sqrt{ }$ \\
\hline Operating device $\mathrm{I}^{2} \mathrm{t}\left(\mathrm{A}^{2} \mathrm{~s}\right)$ & $1.82 \times 10^{7}$ & $5.00 \times 10^{6}$ & $\sqrt{ }$ & $\sqrt{ }$ \\
\hline Maximum symetric voltage $(\mathrm{kV})$ & 25 & 6 & 25 & $?$ \\
\hline Recovery to half voltage $(\mu \mathrm{s})$ & 1 & $1.5-500$ & 1 & $\sqrt{ }$ \\
\hline
\end{tabular}

would avoid snubber requirements by turning off at, or very near the natural current zero, therefore passive recovery within $1 \mu \mathrm{s}$. These two characteristic would minimize or eliminate any snubber volume and mass. Finally, table VIII lists the characteristics of a yet to be developed switching device. For comparison, some typical values for a silicon SCR and Maxwell's TVS-40 vacuum gap ${ }^{7}$ switch is given. The column for a large section silicon-carbide SCR is provided since developments in this material has high potential to answer this class of switching needs. This technology should be expected in the 2010 AD time frame if development funding materializes. Until then, optimized silicon and/or vacuum switches can provide partial solutions to railgun switching needs.

\section{Conclusions}

The results of switch development efforts in three air-core compulsator systems for railgun propulsion have been examined. The comparisons have been used to derive implications for future switch development potential for this type of application and to sketch the outline of a desirable switch element required to realize a $20 \mathrm{MJ}$ electric gun system. A significant improvement in switching density is needed and improved voltage hold-off and switch speed are seen as the keys toward major progress in meeting this goal.

\section{Acknowledgments}

Packaging design for the CCEML and Task-C projects were done by Mr. Randy Lee and that of SmCal by Mr. Don Cooper, both of CEM-UT. CCEML electrical design was directed by Mr. Dave Wehrlen and the other two projects by the author.

The Small Caliber EM Launch System project was sponsored by U.S. Army Armament Research, Development, and Engineering Center (U.S. Army ARDEC) under contract number DAAA21-87-C-0206. The Cannon Caliber EM Gun program is sponsored by U.S. Army ARDEC under contract number DAAA21-92-C-0060 The 9 MJ EM Range Gun System was sponsored by the U.S. Army ARDEC and the Defence Advance Research Projects Agency (DARPA) under contract number DAAA21-86-C-0281.

\section{References}

[1] R.F. Thelen and J.H. Price, "Power Electronics in the 9 MJ EM Range Gun System," 8th Pulsed Power Conference, San Diego, CA, June 17 to $19,1991$.

[2] R.F. Thelen, et al, "Solid-State Switch Development for High Power Pulse Discharge Control," 1990 Nineteenth Power Modulator Symposium, June 26-28, 1990.

[3] D.J. Wehrlen, et al, "Power Electronics and Controls for Air Core Compulsator," 7th EML Symposium on Electromagnetic Launch Technology, San Diego, CA, April 20-24, 1994.

[4] R.L. Fuller, et al, "Testing of an Air Core Compulsator Driven 0.60 Caliber Railgun System," 7th EML Symposium on Electromagnetic Launch Technology, San Diego, CA, April 20-24, 1994.

[5] R.A. Lee,et al, "Design and Testing of a Coaxial Opening and Solid State Closing Switch for the Cannon Caliber Electromagnetic Launcher System (CCEML)," submitted to the 10th IEEE International Pulsed Power Conference, Albuquerque, NM, July 10-13, 1995.

[6] J.D. Herbst, et al, "Status of the 9 MJ Range Gun System," 7th EML Symposium on Electromagnetic Launch Technology, San Diego, CA, April 20-24, 1994.

[7] Maxwell Laboratories, Inc. 8888 Balboa Ave., San Diego CA 92123. 